\title{
Effectiveness of a Single Physician-led Weight loss Program in Primary Care Setting
}

\author{
Varalakshmi Niranjan $^{1}$, Aleksandra Sliwinska ${ }^{1}$, Fufei Chen ${ }^{1}$, Srinath Ramanan ${ }^{1}$, Narinder \\ Maheshwari $^{1}$, and Helen $\mathrm{Wu}^{1}$ \\ ${ }^{1}$ University of Connecticut School of Medicine
}

April 30, 2021

\begin{abstract}
Abstract Objective The aim of this study is to examine the effectiveness of a single physician-led weight loss program in a primary care. Methods This is a retrospective analysis of 300 patients with a BMI $>30 \mathrm{~kg} / \mathrm{m} 2$ in an outpatient weight loss program. Weight loss interventions included lifestyle counseling and pharmacotherapy. Outcomes were assessed based on percentage weight change during a time period of two consecutive visits less than 90 days. Results We found that $57.7 \%$, $43.3 \%$ and $16.1 \%$ patients who attended the clinic 5 or more times, $4-5$ times, 2-3 times respectively achieved $5 \%$ weight loss $(\mathrm{p}<$ 0.0001). In regard to achieving $10 \%$ weight loss, $42.3 \%, 8.7 \%$ and $4.3 \%$ patients who attended the clinic 5 or more times, $4-5$ times and $2-3$ times did it respectively $(\mathrm{p}<0.0001)$. Moreover $60 \%$ of patients achieved $5 \%$ of weight loss in about 200 days, and $40 \%$ achieved $10 \%$ weight loss in 350 days. Patients who achieved $5 \%$ weight loss, their average A1c was reduced to 5.8 at their last visit from 6.4 at the first visit. Conclusions A single physician-led weight loss program is effective and can be created within a primary care setting to achieve $5-10 \%$ weight loss.
\end{abstract}

Title: Effectiveness of a single physician-led weight loss program in primary care setting

Varalakshmi Niranjan MD, MBA, FACP ${ }^{1}$, Aleksandra Sliwinska $\mathrm{MD}^{1}$, Fufei Chen $\mathrm{BS}^{3,4}$, Srinath Ramanan $\mathrm{BS}^{1}$, Narinder Maheshwari MD ${ }^{1}$, Helen $\mathrm{Wu} \mathrm{PhD}^{2,4}$

Department of Medicine ${ }^{1}$

Department of Psychiatry ${ }^{2}$

Department of Statistics ${ }^{3}$

Connecticut Convergence Institute for translation in Regenerative Engineering ${ }^{4}$

UCONN Health

Farmington, CT 06030

Short Title: Single physician-led weight loss program in primary care

Keywords: Obesity, weight loss, clinical care

Corresponding author:

Varalakshmi Niranjan MD, MBA, FACP

Department of Medicine

UCONN Health

65 Kane Street 
West Hartford- 06119

E-mail: niranjan@uchc.edu

Reprint request to be sent to corresponding author.

No grants associated with the work.

No disclosures.

Declarations

No acknowledgements.

No funding to declare.

No conflict of interest.

The study was approved by the Institutional Review Board.

AS wrote the first draft of the manuscript. All authors reviewed and edited the manuscript and approved the final version of the manuscript and any revised version.

The authors confirm that the data supporting the findings of this study are available within the article [and/or] its supplementary materials.

\section{Abstract \\ Objective}

The aim of this study is to examine the effectiveness of a single physician-led weight loss program in a primary care.

\section{Methods}

This is a retrospective cohort analysis of 300 patients with a BMI $>30 \mathrm{~kg} / \mathrm{m}^{2}$ in an outpatient weight loss program. Weight loss interventions included lifestyle counseling and pharmacotherapy. Outcomes were assessed based on percentage weight change during a time period of two consecutive visits less than 90 days.

\section{Results}

We found that $57.7 \%, 43.3 \%$ and $16.1 \%$ patients who attended the clinic 5 or more times, $4-5$ times, $2-3$ times respectively achieved $5 \%$ weight loss $(\mathrm{p}<0.0001)$. In regard to achieving $10 \%$ weight loss, $42.3 \%$, $8.7 \%$ and $4.3 \%$ patients who attended the clinic 5 or more times, $4-5$ times and 2-3 times did it respectively $(\mathrm{p}<0.0001)$. Moreover $60 \%$ of patients achieved $5 \%$ of weight loss in about 200 days, and $40 \%$ achieved $10 \%$ weight loss in 350 days. Patients who achieved $5 \%$ weight loss, their average A1c was reduced to 5.8 at their last visit from 6.4 at the first visit.

\section{Conclusions}

A single physician-led weight loss program is effective and can be created within a primary care setting to achieve $5-10 \%$ weight loss.

\section{Details and Comments}

What is already known about this subject?

1. Primary care interventions for weight management are effective.

2. Weight management counseling declined in primary care practice.

3. Barriers to effective screening, diagnosis, and management are extensive and unique models are needed to address them.

What does this article add? 
1. Single physician-led weight loss program is an effective model in primary care practice.

2. Weight loss of $5-10 \%$ can be effectively achieved with limited resources and without multidisciplinary team.

3. It takes about 200 days to achieve $5 \%$ weight loss and 350 days to achieve $10 \%$ weight loss.

\section{Introduction}

Obesity continues to be devastating public health, economic, and health care challenge. The increasing obesity among adults, children, and adolescents since 1980 is becoming a global health concern [1]. Over the past four decades, the prevalence of obesity worldwide has nearly doubled [2]. In the United States, the prevalence of obesity has increased from 1999-2000 through 2017-2018, from $30.5 \%$ to $42.4 \%$ [3]. It is projected at the current rate the prevalence of obesity will be more than $50 \%$ in 29 states by 2030 [4].

Obesity is a chronic, recurrent multifactorial disease and the outcome depends on genetic, economic, environmental, and behavioral determinants [5]. With a multidisciplinary team as the gold standard, a weight management team (including nutritionists, behavioral psychologists, endocrinologists, bariatric surgeons) is a key to successful management. With strong patient engagement, early intervention by referring to weight loss programs can offer clinically beneficial success [6]. However, access to such care is very limited. Compounding with less availability of obesity treatment and increasing obesity in our society, data further showed that only $25 \%$ patients with obesity were offered dietary counselling, less than $5 \%$ referral, and $2 \%$ weight reducing medications [7]. Based on National Survey between 2005 and 2006, almost two-thirds of patients with obesity in the USA were not offered or referred to weight loss management during their primary care visit [8]. Thus, despite the evidence-based guidelines, the care to patients with obesity for weight loss in primary care remains suboptimal [9].

Barriers to effective screening, diagnosis, and management are extensive, in part due to previous lack of success in weight loss, patient's dissatisfaction with care, and limited time during regular visits. [10]. Even though studies have demonstrated that primary care interventions for weight management are effective, only few evaluated how overweight and obese patients are being managed in the primary care setting [11-12]. Of all primary care visits, less than $30 \%$ were visits associated with obesity diagnosis, and up to $90 \%$ of patients with obesity have not received formal diagnosis $[9,13]$. Further, weight management counseling declined from $33 \%$ to $21 \%$ between from year 2008 to 2013 [13]. At the current rate of increasing obesity prevalence and less availability of weight management counseling, a better obesity care model that can be delivered by primary care physicians is essential since the evaluation of patients with obesity is a complex process, requiring time and diligence from healthcare providers. With this background, a weight management program was created in a University-based academic primary care practice with limited resources. This retrospective study will examine the effectiveness of the program and will discuss the challenges and success of the program.

\section{Methods}

A novel weight management program was established in a University-based primary care practice in 2018. The practice includes a group of 47 primary care providers who were encouraged to refer patients to this program. Patients age above 18 and BMI more than $30 \mathrm{~kg} / \mathrm{m}^{2}$ were referred to the program. This program was managed by a primary care physician who is board-certified in obesity medicine. The program was scheduled for one specific day every week and patients were scheduled for 40 minutes for the initial consultation. During this initial visit, patients had a detailed history, physical examination, and body composition assessment with InBody $270{ }^{\circledR}$ scale and necessary laboratory tests like Hemoglobin A1c, Basic metabolic panel, Thyroid Stimulating Hormone. At the end of this visit, the physician provided them with individualized meal plans, food journal app education, exercise ideas, and strategies to control cravings. An individualized treatment plan was outlined based on the four pillars of obesity management namely Nutrition, Physical activity, Behavioral therapy and Pharmacotherapy. Patients were given a follow up in 4-8 weeks for a subsequent visit. Follow up visits were scheduled for 20 minutes. During these follow up visits, patients were reassessed on a body composition scale and goals were discussed. Counselling was provided based on the need. The reported comorbidities included pre-diabetes, diabetes, hypertension, hyperlipidemia, cardiovascular disease, 
sleep apnea, osteoarthritis, malignancy, depression, and polycystic ovarian syndrome. Pharmacotherapy of obesity included metformin, phentermine, topiramate, bupropion, naltrexone, and GLP-1 agonists.

Weight loss interventions included motivational interviewing, dietary and exercise counseling, behavioral training. Treatment was escalated with pharmacotherapy to treat obesity when appropriate.

\section{Data collection}

This was a retrospective cohort study analyzing data from the electronic medical records of all patients who attended this program from October 1, 2018 to January 31, 2021. The inclusion criteria included age 18 years and older, BMI $=$ or $>30$, and at least one valid follow-up visit in the program. Exclusion criteria patients younger than $18, \mathrm{BMI}<30$, only baseline visit or no valid follow-up visits in the program. The study was approved by the University of Connecticut Internal Review Board.

Outcomes: $5 \%$ or $10 \%$ weight reduction was calculated based on the time for the first and the last valid visits.

Explanatory variables: A valid follow-up visit was defined as a follow-up visit within 90 days after a first visit. The visits were considered as new visits if they were outside this consecutive 90-day period. Patient's longest, continuous visits where were less than 90 days between visits) was used to calculate for the number of valid visits, which was then categorized into $2-3,4-5$, and $5+$ visits. In addition, the secondary outcome was the continuous days a patient stayed in the program.

Other covariates include age, gender, comorbidities (listed above), and medications (listed above) were assessed and documented at each visit and included in the analysis. Hemoglobin A1c was obtained when available.

\section{Analysis}

Descriptive analyses were reported, chi-square or t-test were performed to comparing differences by different levels of visits. In addition, among those who had more than 2 valid visits, the time to achieve $5 \%$ weight loss and $10 \%$ weight loss was analyzed and displayed using Kaplan-Meier Analysis. Statistical estimates with a significance level at $\mathrm{p}<0.05$ were reported. The data analysis for this paper was generated using SAS/STAT software 9.4. Copyright (C) SAS Institute Inc., Cary, NC, USA.

\section{Results}

From October 1, 2018, to January 31, 2020, 300 patients were referred and showed at the one-day-a-week obesity program at a university primary care clinic (Table 1). At baseline (their first visit), Patients reported an average age of 48 years, BMI of 39, over 2 of any comorbidities and 1.8 types of medications, and $85 \%$ were female. The average age of patients who visited the program two or more times was about 50 years old, which is significantly older than those who visited only once (age $=48)(\mathrm{p}=0.03)$. The former group had about two medications prescribed (mean=2.2), more than the latter group did (mean=1.2) $(\mathrm{p}<0.01)$. There were other statistical differences in other characteristics between these two groups.

Table 1. Characteristics of Patients who attended an obesity program in a primary care clinic between November 2018 to January $2020(\mathrm{n}=300)$

\begin{tabular}{lllll}
\hline & Total $(\mathrm{N}=300)$ & 1 Visit $(\mathrm{N}=137)$ & $2+$ visits $(\mathrm{N}=163)$ & $p$-values \\
\hline & Mean (SD) & Mean (SD) & Mean (SD) & \\
Age (in years) & $48.1(13.5)$ & $46.2(13.1)$ & $49.7(13.6)$ & 0.03 \\
Gender, \%(n) & & & & \\
Female Male & $85.0 \%(255) 15.0 \%$ & $83.2 \%(114) 16.8 \%$ & $86.5 \%(141) 13.5 \%$ & 0.41 \\
& $(45)$ & $(23)$ & $(22)$ & \\
Days in the & $\mathrm{NA}$ & $0(0)$ & $248.2(231.2)$ & \\
Program (days) & & & &
\end{tabular}




\begin{tabular}{|c|c|c|c|c|}
\hline & Total $(\mathrm{N}=300)$ & 1 Visit $(\mathrm{N}=137)$ & $2+$ visits $(\mathrm{N}=163)$ & $p$-values \\
\hline $\begin{array}{l}\text { Baseline } \\
\text { Comorbidity }\end{array}$ & $2.3(1.7)$ & $2.2(1.8)$ & $2.4(1.7)$ & 0.17 \\
\hline $\begin{array}{l}\text { Baseline } \\
\text { Medication }\end{array}$ & $1.8(1.5)$ & $1.2(1.3)$ & $2.2(1.6)$ & $<0.01$ \\
\hline Baseline BMI & $40.2(8.3)$ & $41.0(9.0)$ & $39.5(7.4)$ & 0.14 \\
\hline $\begin{array}{l}\% \text { of patients } \\
\text { who achieved } \\
5 \% \text { Weight } \\
\text { Reduction (n) }\end{array}$ & $\mathrm{NA}$ & $\mathrm{NA}$ & $30.7 \%(50)$ & \\
\hline $\begin{array}{l}\text { Reduction (n) } \\
\% \text { of patients } \\
\text { who achieved } \\
10 \% \text { Weight } \\
\text { Reduction (n) }\end{array}$ & NA & NA & $14.1 \%(23)$ & \\
\hline
\end{tabular}

In Table 2, 47.3\% $(\mathrm{n}=142)$ had at least two visits within 90 days and $7 \%(\mathrm{n}=21)$ had a least two visits more than 90 days in-between. There is not statistical difference found in age, gender, baseline BMI by different levels of visits. Patients who reported more than 90 days between visits reported having more comorbidities (3.2) than those who reported visits within 90 days $(2.3)(\mathrm{p}=0.03)$. Those who reported visits within 90 days were prescribed more medications (2.3), than did those visits $>90$ days $(1.7)(\mathrm{p}<0.01)$. In addition, $12 \%$ of the former group achieved $10 \%$ weight loss comparing to the $29 \%$ of the latter group $(\mathrm{p}<0.04)$. There was no statistical group difference in achieving $5 \%$ weight reduction from baseline $(\mathrm{p}=0.07)$ among those with at least 2 visits within 90 days $(n=142), 65 \%(n=93)$ two to three times, while $16 \%(n=23)$ four to five times and $18 \%(\mathrm{n}=26)$ more than five times, indicating $35 \%$ had their follow-up visits for one year and more.

Table 2 . Characteristics of patients who attended an obesity program more than once within or without 90 days $(\mathrm{N}=163)$.

Days between visits

\begin{tabular}{|c|c|c|c|c|c|}
\hline & & $\begin{array}{l}<=90 \text { days* } \\
(\mathrm{N}=142)\end{array}$ & $\begin{array}{l}<=90 \text { days } * \\
(\mathrm{~N}=142)\end{array}$ & $\begin{array}{l}>90 \text { days } \\
(\mathrm{N}=21)\end{array}$ & \\
\hline & & Mean (SD) & Mean (SD) & Mean (SD) & $p$-values \\
\hline $\begin{array}{l}\text { Age (in } \\
\text { years) }\end{array}$ & & $49.6(12.7)$ & $49.6(12.7)$ & $50.4(18.6)$ & 0.09 \\
\hline $\begin{array}{l}\text { Gender, } \\
\%(n)\end{array}$ & & & & & \\
\hline Female Male & & $\begin{array}{l}85.9 \%(122) \\
14.1 \%(20)\end{array}$ & $\begin{array}{l}85.9 \%(122) \\
14.1 \%(20)\end{array}$ & $\begin{array}{l}90.5 \% \text { (19) } 9.5 \% \\
(2)\end{array}$ & 0.61 \\
\hline $\begin{array}{l}\text { Baseline } \\
\text { BMI }\end{array}$ & & $39.3(7.3)$ & $39.3(7.3)$ & $40.6(8.3)$ & 0.28 \\
\hline $\begin{array}{l}\text { Baseline } \\
\text { Comorbidity }\end{array}$ & & $2.3(1.6)$ & $2.3(1.6)$ & $3.2(2.2)$ & 0.03 \\
\hline $\begin{array}{l}\text { Baseline } \\
\text { Medication }\end{array}$ & & $2.3(1.6)$ & $2.3(1.6)$ & $1.7(1.5)$ & $<0.01$ \\
\hline $\begin{array}{l}5 \% \text { Weight } \\
\text { Reduction }\end{array}$ & $\begin{array}{l}\text { 5\% Weight } \\
\text { Reduction }\end{array}$ & $28.2 \%(40)$ & $47.6 \%(10)$ & $47.6 \%(10)$ & 0.07 \\
\hline
\end{tabular}




\begin{tabular}{llcccc}
$\begin{array}{l}\mathbf{1 0 \%} \text { Weight } \\
\text { Reduction }\end{array}$ & $\begin{array}{l}\mathbf{1 0 \%} \text { Weight } \\
\text { Reduction }\end{array}$ & $12.0 \%(17)$ & $28.6 \%(6)$ & $28.6 \%(6)$ & 0.04 \\
\hline
\end{tabular}

There is no statistical difference in patients' age, gender and comorbidities by levels of visits. Patients who had more visits reported higher number of medications prescribed $(\mathrm{p}<0.001)$. In regard to achieving $5 \%$ weight loss, $57.7 \%, 43.3 \%$ and $16.1 \%$ patients who attended the clinic 5 or more times, $4-5$ times, $2-3$ times respectively did so $(\mathrm{p}<0.0001)$. In regard to achieving $10 \%$ weight loss, $42.3 \%, 8.7 \%$ and $4.3 \%$ patients who attended the clinic 5 or more times, $4-5$ times and $2-3$ times did it respectively $(\mathrm{p}<0.0001)$.

Table 3. Characteristics of patients who attended an obesity program more than once within 90 days $(\mathrm{N}=142)$.

\begin{tabular}{|c|c|c|c|c|}
\hline & $2-3$ visits $(\mathrm{N}=93)$ & $4-5$ visits $(\mathrm{N}=23)$ & $5+$ visits $(\mathrm{N}=26)$ & $5+$ visits $(\mathrm{N}=26)$ \\
\hline & Mean (SD) & Mean (SD) & Mean (SD) & $p$-values \\
\hline Age (in years) & $48.6(12.4)$ & $47.7(12.7)$ & $53.8(13.5)$ & 0.15 \\
\hline Gender & & & & 0.56 \\
\hline Female Male & $85.0 \%(79) 15.0 \%(14)$ & $82.6 \%$ (19) $17.4 \%(4)$ & $92.3 \%(24) 7.7 \%(2)$ & \\
\hline Comorbidity & $2.2(1.7)$ & $2.6(1.2)$ & $2.6(1.6)$ & 0.30 \\
\hline Medication & $1.9(1.4)$ & $2.9(1.5)$ & $3.2(1.6)$ & $<0.0001$ \\
\hline 5\% Weight Reduction & $16.1 \%(15)$ & $43.5 \%(10)$ & $57.7 \%(15)$ & $<0.0001$ \\
\hline 10\% Weight Reduction & $4.3 \%(4)$ & $8.7 \%(2)$ & $42.3 \%(11)$ & $<0.0001$ \\
\hline
\end{tabular}

In Figure 1, 60\% of patients achieved 5\% of weight loss in about 200 days, and $40 \%$ achieved $10 \%$ weight loss in about 350 days. Patients who achieved $5 \%$ weight loss, their average A1c was reduced to 5.8 at their last visit from 6.4 at the first visit if the length of at least two consecutive visits is less than 90 days (not reported in figures and tables).

\section{Discussion}

This current study demonstrates that single physician-led weight loss program can be successfully implemented in a primary care setting and supports the hypothesis that patients with obesity are able to achieve $5 \%$ and $10 \%$ weight loss goals in such program. About one third $(28.2 \%)$ of our patients achieved $5 \%$ weight loss within 90 days. These findings align with several previous studies of similar results, yet we describe the unique effectiveness of a single physician-led, personalized, weight loss program with minimal resources. Davis Martin et al. performed a study to determine the effectiveness of a primary care weight loss intervention African American women with obesity where the intervention group received monthly 15 minutes visits for six months and during which physicians provided tailored health, exercise and dietary recommendations assembled by a multidisciplinary group with the intervention group (12.5\%) achieving [?] $5 \%$ weight loss vs. $3(5.2 \%)$ of standard care participants [14]. Bowerman et al. compared the effectiveness of a ten-minute primary care physician- led intervention plus dietician-led telephone counseling session versus usual care on patients' satisfaction and weight loss. They concluded that their program was effective and resulted in about $9.5 \%$ and $6.5 \%$ weight loss from baseline for women and men at 6 months follow-up, respectively, when considering the averages [15]. These studies parallel our statement that the primary care setting is a successful area to implement weight management interventions. Our novel description underscores the effectiveness of a single physician trained in obesity medicine, without the help of a multidisciplinary team, achieving clinically significant weight loss within a year. This highlights the potential for primary care physicians to be trained in obesity medicine and positively intervene for weight control, even with limited time and resources.

Weight loss is a long-term process, and as we see in this study, majority of patients achieved significant weight loss in about 200 days. Those who stayed in the program longer were more likely to achieve significant weight loss ( $5 \%$ weight loss when follow up visits were within 90 days period). Therefore, patients' retention in the 
weight loss program remains a key to the success and this should be emphasized to the patients at each visit. For adults with overweight or obesity, the longer follow-up period the better weight loss outcomes not only in achieving goals but also maintaining weight [16-17]. In Cohen et al.'s study investigating weight loss in patients with obesity and hypertension, those who lost weight saw their physicians more frequently, whether in the intervention group or not, and also ended up with less antihypertensive medications at the end of the study [18]. It is evident that patient's engagement, even with minimal intervention, results in more positive patient's outcomes. This follow-up period is essential for ongoing supervision, continued education, and positive reinforcement to reap the long-term benefits of clinically significant weight loss. More primary care physicians should be trained in obesity medicine and be supported by hospital management and insurance companies to schedule patients with obesity more frequently. This will create accountability to patients and improve the outcome.

Obesity is directly related with multiple metabolic comorbidities, significant mortality and tremendous healthcare costs. Weight loss studies demonstrated that improvement in all metabolic components of obesity can be seen with $5-10 \%$ weight loss [19]. Higher weight loss goals may be required to improve mortality outcomes [20]. In view of healthcare costs related to overweight and obesity, significant reduction in hospitalizations, medications cost in patients with diabetes was observed with again 5-10\% weight loss [21]. Sustained remission of type 2 diabetes has been achieved in more than third of patients who maintained at least $10 \mathrm{~kg}$ weight loss [22]. Our study found similar impact of $5 \%$ weight loss on hemoglobin A1c which decreased from average $6.4 \%$ at the first visit to $5.8 \%$ at the last visit. Hence, the greater the weight loss, the better improvement in metabolic components and complications of obesity which, as we prove, can be successfully achieved in single physician-led weight loss program.

Finally, it is important to note the challenge of adherence to weight loss intervention and maintain scheduled follow up visits throughout this study due to the ongoing uncertainty of COVID-19 and visit cancellations. In our study nearly half patients visited the clinic only once. Patient's dropout rates differ among studies with attrition varying between 30-81.5\% [23-24]. This particular challenge has many underlying reasons. Factors affecting attendance and adherence to interventions include psychosocial (stress, depression, social support), socio-demographic (age, employment, education) and behavioral (previous failed weight loss attempts) aspects [24]. To improve the efficiency of physician-led weight loss, these barriers to compliance need to be addressed. High adherence was observed in the interventions incorporating social support (peer coaches, involving family, and buddy programs) [25]. With the recent burst of telemedicine, the availability of telephone and video visits have a great potential to overcome access or resource barriers. Motivation as an important factor, can be monitored by questionnaire at each visit to identify these patients who may need more time spent on coaching, positive reinforcement and finding psychosocial aspects that interfere with adherence. Improving self-monitoring by behavioral strategies like electronic diet diaries may also improve attendance and patients' engagement. In future studies, there are grounds for better understanding attrition barriers and improvement in patients' engagement in the weight loss program.

\section{Conclusion}

A single physician-led weight loss program is a unique model of weight loss management that can be successfully introduced in the primary care setting with proper training even with limited resources and without multidisciplinary team. This practice can achieve $5 \%$ and $10 \%$ weight loss in patients with obesity, along with improvement in metabolic components. Weight loss is a long process, as about $60 \%$ of patients will take up to 200 days to achieve $5 \%$ weight loss. Although adherence and attendance are important predictors of weight loss, they can be improved by addressing patient-specific barriers and creating practice-based methods to improve follow-up rates and patients' engagement.

\section{References}

1. GBD 2015 Obesity Collaborators, Afshin A, Forouzanfar MH, et al. Health Effects of Overweight and Obesity in 195 Countries over 25 Years. N Engl J Med . 2017;377(1):13-27.

2. Arroyo-Johnson C, Mincey KD. Obesity Epidemiology Worldwide. Gastroenterol Clin North Am . 
2016;45(4):571-579.

3. Hales CM, Carroll MD, Fryar CD, Ogden CL. Prevalence of Obesity and Severe Obesity Among Adults: United States, 2017-2018. NCHS Data Brief . 2020;(360):1-8.

4. Ward ZJ, Bleich SN, Cradock AL, et al. Projected U.S. State-Level Prevalence of Adult Obesity and Severe Obesity. N Engl J Med . 2019;381(25):2440-2450.

5. Smith KB, Smith MS. Obesity Statistics. Prim Care . 2016;43(1):121-ix.

6. Fitzpatrick SL, Wischenka D, Appelhans BM, et al. An Evidence-based Guide for Obesity Treatment in Primary Care. Am J Med . 2016;129(1):115.e1-115.e1157.

7. Booth HP, Prevost AT, Gulliford MC. Access to weight reduction interventions for overweight and obese patients in UK primary care: population-based cohort study. BMJ Open . 2015;5(1):e006642.

8. Ma J, Xiao L, Stafford RS. Adult obesity and office-based quality of care in the United States. Obesity (Silver Spring) . 2009;17(5):1077-1085.

9. Fitzpatrick SL, Stevens VJ. Adult obesity management in primary care, 2008-2013. Prev Med . 2017;99:128-133.

10. Kahan SI. Practical Strategies for Engaging Individuals With Obesity in Primary Care. Mayo Clin Proc . 2018;93(3):351-359.

11. Booth HP, Prevost TA, Wright AJ, Gulliford MC. Effectiveness of behavioural weight loss interventions delivered in a primary care setting: a systematic review and meta-analysis. Fam Pract . 2014;31(6):643653.

12. Leblanc ES, O'Connor E, Whitlock EP, Patnode CD, Kapka T. Effectiveness of primary care-relevant treatments for obesity in adults: a systematic evidence review for the U.S. Preventive Services Task Force. Ann Intern Med . 2011;155(7):434-447.

13. Crawford AG, Cote C, Couto J, et al. Prevalence of obesity, type II diabetes mellitus, hyperlipidemia, and hypertension in the United States: findings from the GE Centricity Electronic Medical Record database. Popul Health Manag . 2010;13(3):151-161.

14. Davis Martin P, Rhode PC, Dutton GR, Redmann SM, Ryan DH, Brantley PJ. A primary care weight management intervention for low-income African-American women. Obesity (Silver Spring) . 2006;14(8):1412-1420.

15. Bowerman S, Bellman M, Saltsman P, et al. Implementation of a primary care physician network obesity management program. Obes Res . 2001;9 Suppl 4:321S-325S.

16. Ahern AL, Wheeler GM, Aveyard P, et al. Extended and standard duration weight-loss programme referrals for adults in primary care (WRAP): a randomised controlled trial [published correction appears in Lancet. 2017 Jun 3;389(10085):2192]. Lancet . 2017;389(10085):2214-2225.

17. Middleton KM, Patidar SM, Perri MG. The impact of extended care on the long-term maintenance of weight loss: a systematic review and meta-analysis. Obes Rev . 2012;13(6):509-517.

18. Cohen MD, D'Amico FJ, Merenstein JH. Weight reduction in obese hypertensive patients. Fam Med . 1991;23(1):25-28.

19. Ryan DH, Yockey SR. Weight Loss and Improvement in Comorbidity: Differences at 5\%, 10\%, 15\%, and Over. Curr Obes Rep . 2017;6(2):187-194.

20. Sjöström L, Narbro K, Sjöström CD, et al. Effects of bariatric surgery on mortality in Swedish obese subjects. N Engl J Med . 2007;357(8):741-752.

21. Espeland MA, Glick HA, Bertoni A, et al. Impact of an intensive lifestyle intervention on use and cost of medical services among overweight and obese adults with type 2 diabetes: the action for health in diabetes. Diabetes Care . 2014;37(9):2548-2556.

22. Lean MEJ, Leslie WS, Barnes AC, et al. Durability of a primary care-led weight-management intervention for remission of type 2 diabetes: 2-year results of the DiRECT open-label, cluster-randomised trial. Lancet Diabetes Endocrinol . 2019;7(5):344-355.

23. Franz MJ, VanWormer JJ, Crain AL, et al. Weight-loss outcomes: a systematic review and meta-analysis of weight-loss clinical trials with a minimum 1-year follow-up. J Am Diet Assoc . 2007;107(10):1755-1767.

24. Leung AWY, Chan RSM, Sea MMM, Woo J. An Overview of Factors Associated with Adherence to 
Lifestyle Modification Programs for Weight Management in Adults. Int J Environ Res Public Health . 2017;14(8):922.

25. Lemstra M, Bird Y, Nwankwo C, Rogers M, Moraros J. Weight loss intervention adherence and factors promoting adherence: a meta-analysis. Patient Prefer Adherence . 2016;10:1547-1559.

\section{Hosted file}

Figure 1.pdf available at https://authorea.com/users/410979/articles/520177-effectiveness-ofa-single-physician-led-weight-loss-program-in-primary-care-setting

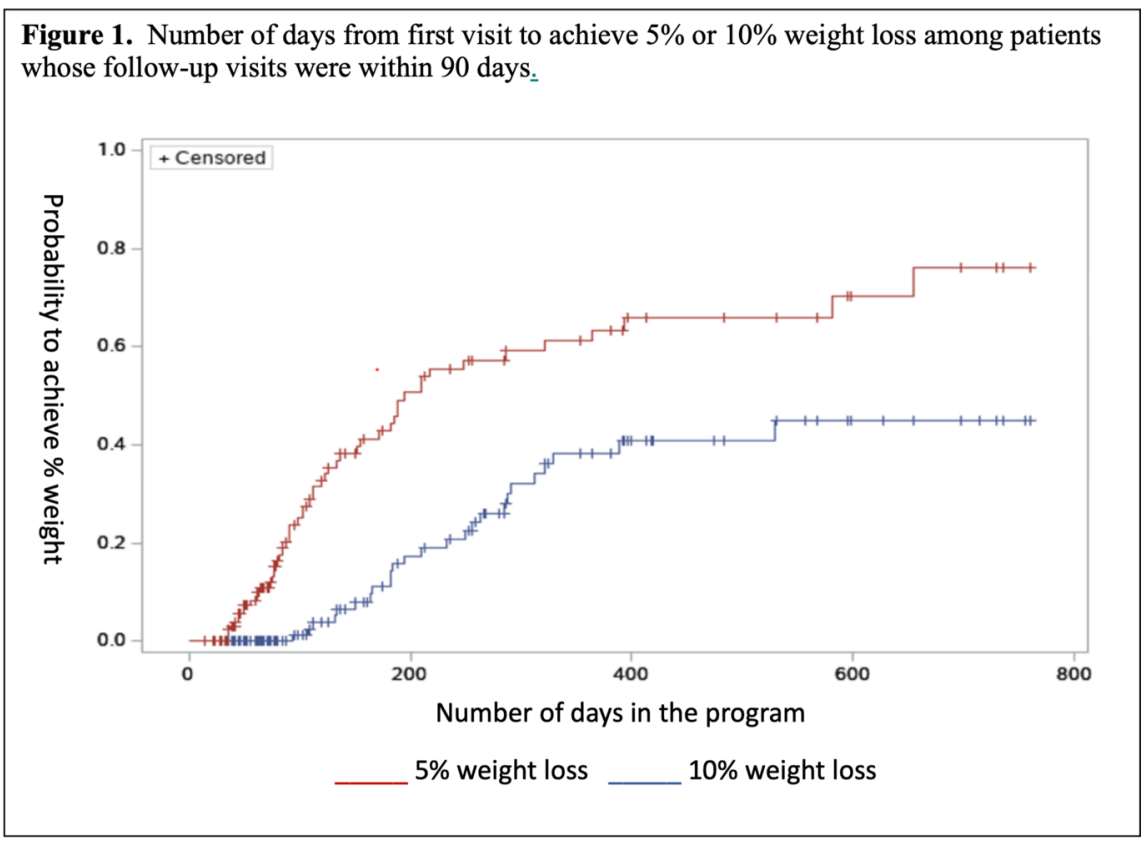

